\title{
PkM Implementasi Tata Nilai-Nilai Integritas Akademisi berbasis Sistematika Penyuluh Antikorupsi bersama LSP P3 Pembangun Penyuluh Integritas Bangsa: Studi Kasus Pembentukan Zona Integritas di Provinsi DKI Jakarta (PkM Implementation of Academic Integrity Values Based on Anti-Corruption Extension Systematics with LSP P3 Development of Nation Integrity Extension: Case Study of Integrity Zone Formation in DKI Jakarta Province)
}

Dewi Puspaningtyas Faeni ${ }^{1}$, Ratih Puspitaningtias Faeni ${ }^{2}$, Retno Fuji Oktaviani ${ }^{3}$, Ravindra Safitra Hidayat ${ }^{4}$

Fakultas Ekonomi dan Bisnis, Universitas Budi Luhur, Jakarta Selatan 1,2,3,4

dewifaeni@budiluhur.ac.id ${ }^{l^{*}}$, ratih.puspitaningtyas@budiluhur.ac.id ${ }^{2}$, retno.fujioktaviani@budiluhur.ac.id ${ }^{3}$,ravindra.safitra@budiluhur.ac.id ${ }^{4}$

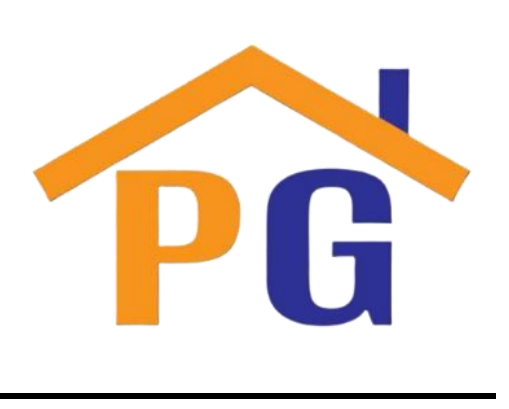

Riwayat Artikel

Diterima pada 3 Juni 2021

Direvisi pada 23 September 2021

Disetujui pada 23 September 2021

\begin{abstract}
Purpose: This Community Service (PKM) aimed to strengthen integrity values by taking preventive measures and promoting educational programs about the dangers of corruption, its causes, and systematic prevention.

Method: This PKM was delivered to the academic community, consisting of Chancellors, Deans, Lecturers, and Students at several campuses throughout the DKI Jakarta Province. This PKM activity was made possible through the PSKK Grant (Work Competency Certification Program) under BNSP.

Results: The added value of participating in the Anti-Corruption Instructor BNSP Certification Program is not only effective at systematic socialization of corruption prevention, but also serves as a Certificate of Companion Diploma (SKPI) for students, lecturers, deans, and rectors. Additionally, according to the survey's graph, recipients of the BNSP Certificate quickly get hired.

Keywords: BNSP Certification, Anti-Corruption Extension, LSP P3 PIB, Employment, Integrity Values

How to Cite: PkM Implementasi Tata Nilai-Nilai Integritas Akademisi berbasis Sistematika Penyuluh Antikorupsi bersama LSP P3 Pembangun Penyuluh Integritas Bangsa: Studi Kasus Pembentukan Zona Integritas di Provinsi DKI Jakarta. Jurnal Nusantara Mengabdi, 1(1), 21-32.
\end{abstract}

1. Pendahuluan

Berdasarkan Perpres RI No. 87/2017, perihal pembentukan karakter bagi peserta didik untuk menciptakan bangsa Indonesia yang berakhlak tinggi, dan memiliki tata nilai integratis, bangga menjadi orang Indonesia, wawasan kebangsaan yang tinggi, cinta damai, gemar membaca, kepedulian pada lingkungan, memiliki kepekaan sosial dan jiwa penolong. Tata nilai integritas di atas memerlukan sistematika pendidikan dalam upaya membentuk karakter bangsa yang mertabat.

Berdasarkan UU RI No. 20/2003 tentang pola sistemasika pendidikan nasional perihal bagaimana meningkatkan moralitas bangsa dengan menjunjung tinggi pendidikan pembentukan akhlak, peningkatan tata nilai integritas. Sementara berlandaskan Permenpan RB No. 10, 2019 perihal tata cara serta pedoman baku pembangun zona integritas menuju kawasan bersih korupsi di wilayah 
birokrasi bebas suap menyuap, gratifikasi pada lingkungan instansi pemerintah saat melayani kepentingan masyarakat.

Pergub No. 87, 2014 perihal sistem pengelolaan dan tata cara gratifikasi, suap meyuap, penegakkan hukumn yang mendasari UU No. 20, 2001 perihal tindak pidana korupsi di lingkungan pemerintah Provinsi DKI Jakarta dan pembentukan zona integritas. Seperti pada Pergub No. 132, 2019 perihal penyelenggaraan pendidikan antikorupsi di seluruh sekolah di Provinsi DKI Jakarta. Ditambah Instruksi Sekda No. 54, 2016 perihal peniadaan praktek-praktek pungutan liar, suap menyuap serta pengaturan perihal gratifikasi yang dituangkan pada Surat Edaran Dinas Pendidikan Prov. DKI Jakarta No. 122/SE/2016. Permendikbud No. 42, 2014 tentang pembangunan zona integritas di lingkungan sekolah dan kampus.

PKM dilaksanakan untuk membangun tata nilai integritas di lingkungan pendidikan. Pengenalan tata nilai di lingkungan pendidikan menjadi wajib. Pada Permenristek No. 44, 2015, perihal standar Nasional Pendidikan tinggi, bahwa setiap mahasiswa yang lulus wajib memiliki kompetensi diindikasikan dengan SKPI (Surat Keterangan Pendamping Ijazah) dalam bentuk Sertifikat kompetensi yang dikeluarkan oleh BNSP.12, 2012 tentang pendidikan tinggi Pasal 44, perihal sertifikat kompetensi merupakan pengakuan kompetensi atas prestasi kelulusan yang sesuai dengan kompetensinya. Dampak utama dari korupsi adalah tingginya tingkat pengangguran berdampak pada melemahnya daya beli masyarakat, kesejahteraan masyarakat menurun, biaya pendidikan yang semakin tidak terjangkau serta tingginya biaya kesehatan serta biaya-biaya yang lain.

Metode pencegahan korupsi memiliki tiga pendekatan, yaitu; preventif, represif dan edukatif. Pendekatan preventif adalah pendekatan pencegahan menggunakan sistem manajemen yang ketat, represif adalah pendekatan seperti yang dilakukan sebagainOperasi Tangkap Tangan (OTT), sedangkan PKM yang dilakukan adalah pendekatan edukatif yang menitik beratkan pada kemampuan mengkomunikasikan tentang bahaya korupsi serta cara-cara metodologi pencegahannya. Terutama dalam meningkatkan Tata Nilai Integritas sebagai ujung tombak diseminasi program PKM ini.

Program PKM ini, diharapkan mendapat pembekalan ilmu mengenai pencetus dan metodologi pencegahan pemebrantasan tindak pidana korupsi. Metodologi dimaksud adalah sistematika menerapkan tata nilai integritas di manapun Asesi berada. Sedangkan penumbuh kembangkan Tata nilai integritas dimaksud adalah sebagai berikut: berakhlak tinggi, menjunjung tata nilai integratis, sopan santun dan budi luhur melalui pendidikan agama religius, kejujuran, toleransi, kedisiplinan, bertanggung jawab, berpendirian keras, memiliki kreatif tinggi, kemandirian, pola pikir yang demokratis, akuntabilitas, semangat nasionalisme yang tinggi, cinta kebangsaan, bangga menjadi orang Indonesia, wawasan kebangsaan yang tinggi, cinta damai, gemar membaca, kepedulian pada lingkungan, memiliki kepekaan sosial dan jiwa penolong. Tata nilai integritas di atas memerlukan sistematika pendidikan tersendiri, harus dibentuknmenggunakan kompetensi khusus sebagai upaya membentuk karakter bangsa yang bermartabat (Creesy, 2018)..

Kalangan Akademisi sebagai pencetak Agent of Change diyakini mampu meningkatkan rasa memiliki, integritas sebagai Bangsa Indonesia untuk menjaga marwah dan menjunjung tata nilai-nilai luhur integritas bangsa yang luhur. Sebagai warga negara yang berintegritas, kelak sebagai pemilik sertifikat BNSP Penyuluh Antikorupsi para Asesi dapat menjadi role model atau panutan dalam menjaga marwah bangsa ini yang mencanangkan 2045 Indonesia Emas sebagegara berdaulat Bebas Korupsi. Disamping itu dalam rangka membentuk lingkungan kampus sebagai Zona Integritas.

Metode pencegahan menggunakan pendekatan preventif dan edukatif agar terhindar dari tindak pidana korupsi, yaitu dengan penerapan peningkatan kompetensi profesi sebagai Penyuluh Antikorupsi bersertifikasi BNSP. Proses sertifikasi BNSP Penyuluh Antikorupsi sebagai bukti nyata pencetak agen perubahan untuk meningkatkan awareness di kalangan Akademisi. Program PKM ini menggandeng LSP P3 PIB (Lembaga Sertifikasi Profesi P3 Pembangun Penyuluh Integritas Bangsa) sebagai mitra pengabdian kepada masyarakat. Sertifikasi BNSP merupakan Lembaga Resmi berkekuatan hukum sebagai perpanjangan tangan dari Departemen Tenaga Kerja dengan mengeluarkan sertifikat lisensi kepada LSP P3 PIB untuk melakukan proses sertifikasi Penyuluh 
Antikorupsi dengan tujuan meningkatkan keterlibatan masyarakat dalam memberantas korupsi. Sumbangsih para Akademisi sebagai Asesi diyakini dapat menumbuhkan semangat perlawanan terhadap Tindak Pidana Korupsi yang tertuang pada UU 20, tahun 2001. Terdapat 7 (tujuh) delik tindak pidana korupsi. Standar Kompetensi Kerja Nasional Indonesia menuangkan ada 20 (duapuluh) Unit Kompetensi Kerja (SKKNI 303, 2016).

Adapun profil para Asesi program PKM adalah para Asesi dimaksud para Rektor, para Wakil Rektor, para Dekan, para Kepala Jurusan, Direktur Riset, dan para mahasiswa di beberapa perguruan tinggindi Provinsi DKI Jakarata, dengan batasan usia antara 19 hingga 60 tahun. Warga negara Indonesia dan memiliki kegiatan atau pekerjaan di lingkungan kampus. Asesi memiliki latar belakang yang beragam dan dibesarkan di dalam iklim pendidikan yang beraneka ragam, maka metodologi sertifikasi pun menggunakan dua pendekatan uji kompetensi tatap muka dan secara daring. Proses Uni Kompetensi berlangsung dalam dua tahapan; uji kompetensi tahap pertama adalah melakukan presentasi Aspek Keselamatan, Kemanan dan Kesehatan Kerja dan Presentasi Materi Dasar Penyuluh Antikorupsi utamanya dalam penerapan tata nilai integritas. Sedangkan pada tahap kedua adalah uji komprehensif perihal penyebab, cara mitigasi dan evaluasi penyuluhan (LSP P3 PIB, 2021).

Tabel 1. Demografis Asesi Berdasarkan Gender

\begin{tabular}{|c|c|l|c|c|}
\hline No. & Asesi & \multicolumn{1}{|c|}{ Lokasi } & Pria & Wanita \\
\hline 1 & Rektor & Tempat Uji Kompetensi LSP P3 PIB & 9 & 1 \\
\hline 2 & Wakil Rektor & Tempat Uji Kompetensi LSP P3 PIB & 12 & - \\
\hline 3 & Direktur & Tempat Uji Kompetensi LSP P3 PIB & 4 & 4 \\
\hline 4 & Dekan & Tempat Uji Kompetensi LSP P3 PIB & 10 & 3 \\
\hline 5 & Kajur & Tempat Uji Kompetensi LSP P3 PIB & 7 & 3 \\
\hline 6 & Mahasiswa & Tempat Uji Kompetensi LSP P3 PIB & 346 & 401 \\
\hline
\end{tabular}

Sumber: Data Primer, 2021

\section{Rumusan Masalah Mitra}

Berdasarkan hasil indentifikasi permasalahan dari para Asesi, bahwa latar belakang pendidikan yang berbeda. Para Asesi juga merasa apatisme dalam membangun negara.

Tabel 2. Data Permasalahan Asesi

\begin{tabular}{|c|l|}
\hline No. & \multicolumn{1}{|c|}{ Permasalahan } \\
\hline 1 & Ingin memiliki negara yang maju \\
\hline 2 & Ingin memiliki negara yang bebas dari korupsi \\
\hline 3 & Ingin memberantas korupsi, tapi tidak tahu bagaimana \\
\hline
\end{tabular}




\begin{tabular}{|c|l|}
\hline 4 & Skeptisme tinggi bahwa korupsi bisa diberantas \\
\hline 5 & Khawatir terhadap masa depan bangsa \\
\hline 6 & Apatis terhadap kebijakan pemerintah \\
\hline 7 & Merasa tidak berdaya sebagai masyarakat \\
\hline 8 & Marah dengan keadaan \\
\hline 9 & Khawatir terhadap pejabat yang menyalah gunakan kekuasaan \\
\hline 10 & Takut Indonesia runtuh \\
\hline
\end{tabular}

\section{Solusi yang Ditawarkan}

Sumber : Hasil survei, April 2021

Megacu pada hasil survei yang dilakukan, maka para Asesi dilibatkan pada program sertifikasi BNSP Penyuluh Antikorupsi berbasis kompetensi dengan aktivitas kebangsan dengan menjalani proses sertifikasi Penyuluh Antikorupsi yang mengacu pada Unit Kerja (UK) terdiri dari 20 (duapuluh) UK berikut lis dari solusi sebagai jawaban dari permasalahan yang dihadapi para Asesi.

Tabel 3. Target Luaran PKM Sertifikasi BNSP Penyuluh Antikorupsi

\begin{tabular}{|l|l|l|}
\hline No. & \multicolumn{2}{|c|}{ Target Jenis Luaran } \\
\hline 1. & Publikasi Ilmiah Nasional & Publikasi pada Jurnal Nasional Terakreditasi \\
\hline 2. & Prosiding, Internasional Conference & IJFAM Scopus Q2 2656-3355 \\
\hline 3. & Desiminasi Program Sertifikasi & $\begin{array}{l}\text { Sosialisasi Penyuluh Integritas Sertifikasi } \\
\text { Penyuluh LSP P3 PIB secara Nasional }\end{array}$ \\
\hline 4. & Mendapat Sertifikat BNSP & Sertifikat Penyuluh Antikorupsi Pratama \\
\hline 5. & $\begin{array}{l}\text { Mendapat penghayatan ilmu } \\
\text { pencegahan Korupsi }\end{array}$ & $\begin{array}{l}\text { Materi Dasar Penyuluh Antikorupsi } \\
\text { Materi Lanjutan Penyuluh Antikorupsi }\end{array}$ \\
\hline 6. & Mendapat ilmu penerapan tata nilai & $\begin{array}{l}\text { Penghayatan kedisiplinan, kejujuran, kemandirian, } \\
\text { bertanggung jawab, saling membantu, saling } \\
\text { peduli, komitmen yang tinggi }\end{array}$ \\
\hline
\end{tabular}

Sumber ; Data Primer LSP PIB, 2021

\section{Metode Pelaksanaan}

Pendidikan Penyuluh Antikorupsi memiliki daya ungkit dan peranan yang sangat efektif dalam proses diseminasi di lingkungan akademisi, karena telah menjadi kurikulum wajib. Untuk itu diperlukan penguatan tacit knowledge melalui sistematika tertera pada Gambar 1. 


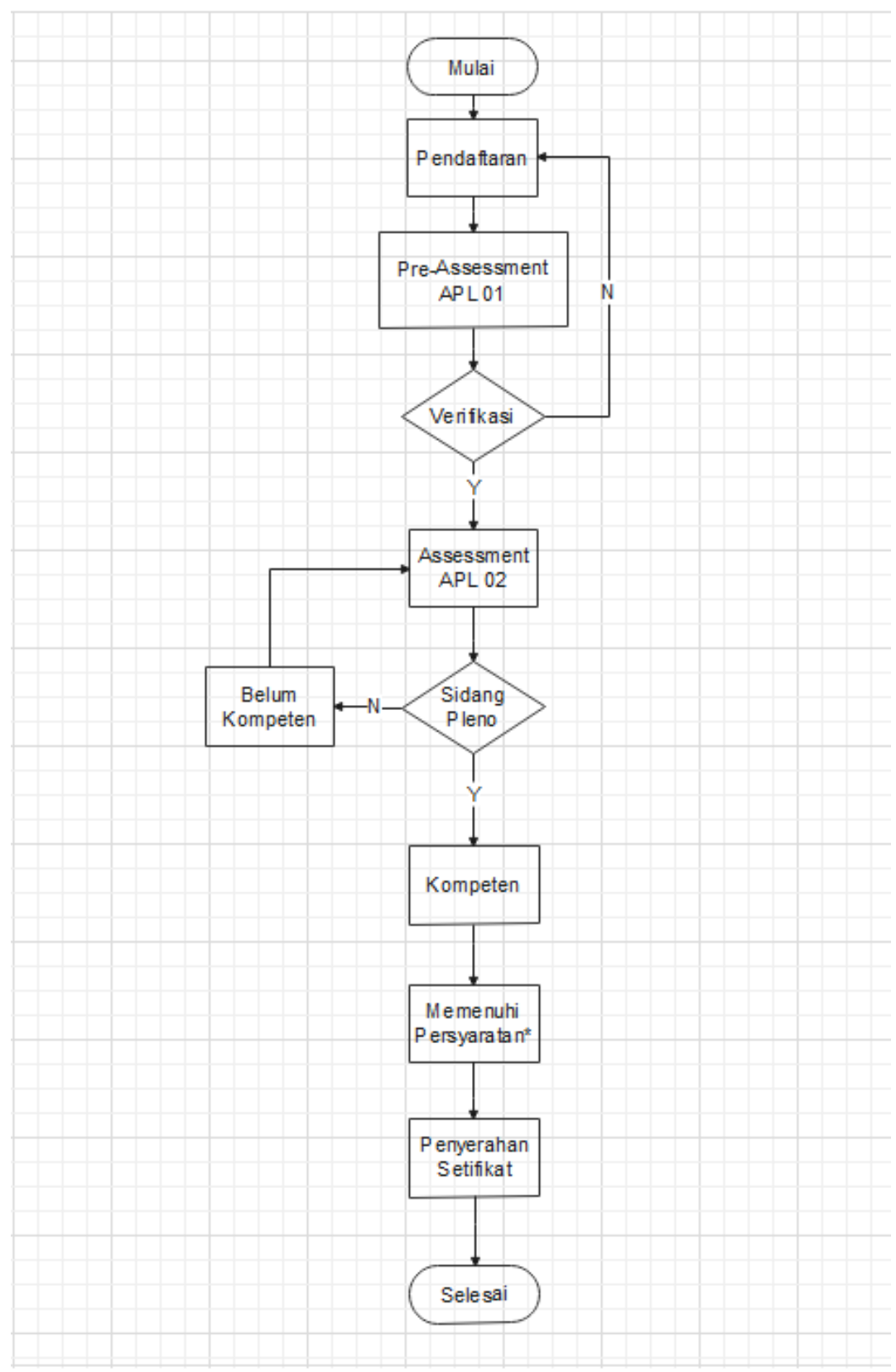

Gambar 1. Proses Sertifikasi Penyuluh Antikorupsi

Sumber: LSP P3 PIB, 2021

Berikut adalah uraian dari Gambar 1. sebagai berikut:

1. Tahap Pertama

Asesi dihadirkan dari berbagai Institusi Pendidikan di lingkungan Pemprov DKI Jakarta, dikelompokkan dalam kategori umur, jenis kelaming dan pengalaman kerja.

2. Tahap Kedua

Diberikan kuliah umum tentang dasar-dasar SKKNI 303/2016 perihal tata laksana Program Sertifikasi BNSP Penyuluh Antikorupsi.

3. Tahap Ketiga

Pengisian Formulir APL-01 dan APL-02 
4. Tahap Empat

Validasi dan Pra Asesmen dilaksanakan verifikasi terhadap Data serta keabsahan Asesi

5. Tahapan Lima

Asesi akan mendapatkan satu Asesor untuk melakukan verifikasi dan validasi dokumen persyaratan pemberkasan.

6. Tahapan Enam

Berkas-berkas persyaratan diverifikasi pada tahapan lanjutan.

7. Tahapan Tujuh

Jika setelah diverifikasi Asesi dinyatakan memenuhi syarat, maka Asesi dapat melanjutkan ke tahapan berikutnya yaitu Uji Kompetensi (Portfolio Presentasi Aspek Keamanan, Kesehatan dan Keselamatan Kerja serta Presentasi Materi Penyuluh Antikorupsi. Uji Kompetensi dilanjutkan ke jenjang Uji Komprehensif.

8. Tahapan Delapan

Hasil Uji Kompetensi para Asesi akan dikumpulkan dalam sebuah rapat Pleno yang dihadiri secara quorum. Tahapan Sembilan

Pengumuman Hasil Rapat Pleno tentang hasil Kompetensi para Asesi.

9. Tahapan Sembilan

Hasil dari Rapat Pleno diumumkan kepada para Asesi.

10. Tahapan Sepuluh

Penyerahan Sertifikat BNSP kepada Asesi yang dinyatakan K atau Kompeten.

\section{Permasalahan}

1) Pelaksanaan kurikulum Antikorupsi belum ada penjelasan yang komprehensif

2) Materi penyuluhan sangat minim

3) Literatur perihal korupsi untuk sosialisasi tidak ada yang baku

4) Budaya korupsi sangat mengakar di Indonesia

5) Asesi berada di lingkungan sangat skeptis perihal masalah korupsi

6) Frekuensi pelanggaran hukum tindak pidana korupsi terjadi hampir setiap hari

7) Penegakkan hukum terhadap tindak pidana korupsi masih sangat lamah tebang pilih

8) Hukum di Indonesia tajam ke bawah tumpul ke atas

9) Rekruitmen Aparatur Sipil Negara (ASN) di KPK (Komite Pemberantasan Korupsi) sangat rentan Kolusi, Korupsi dan Nepotisme (KKN)

10) Adanya kejanggalan saat rekruitmen ASN mengisi pertanyaan wawasan kebangsaan

\section{Solusi dan Output}

Tabel 4. Unit Kompetensi Sebagai Solusi Yang Ditawarkankan

\begin{tabular}{|c|l|l|}
\hline No & \multicolumn{1}{|c|}{ Uraian } & \multicolumn{1}{|c}{ Solusi } \\
\hline $\mathbf{1}$ & Mengaktualisasikan Nilai-Nilai Integritas & Membangun wawasan kebangsaan \\
\hline $\mathbf{2}$ & Menangani Konfllk yang Muncul dalam Proses Penyuluhan Antikorupsi & Membangun cara berpikir kritis \\
\hline $\mathbf{3}$ & Menerapkan Aspek K-3 dalam Pelaksaanan Penyuluhan Antikorupsi & Mitigasi Aspek K3 Pandemi \\
\hline $\mathbf{4}$ & Menumbuhkan Semangat Perlawanan terhadap Korupsi & $\begin{array}{l}\text { Melakukan penyuluhan perihal } \\
\text { nahaya }\end{array}$ \\
\hline $\mathbf{5}$ & Menyadarkan Bahaya dan Dampak Korupsi Termasuk Perilaku KKN & Membangun metodologi pencegahan \\
\hline $\mathbf{6}$ & Membangun Cara Berpikir Kritis terhadap Masalah Korupsi & Membangun sistematika kronologis \\
\hline $\mathbf{7}$ & Meningkatkan Pengetahuan Terkait Antikorupsi & Meningkatkan tacit knowledge \\
\hline $\mathbf{8}$ & Meningkatkan Keterampilan Antikorupsi & Membangun teknik menyuluh \\
\hline
\end{tabular}




\begin{tabular}{|c|c|c|}
\hline No & Uraian & Solusi \\
\hline 9 & Membangun Sikap Antikorupsi & Melakukan analisis kasus incracht \\
\hline 10 & Menumbuhkembangkan Kelembangaan Antikorupsi & Membentuk kelompok antikorupsi \\
\hline 11 & Mendorong Kemandirian Kelompok Sasaran & Memberikan metodologi antikorupsi \\
\hline 12 & Menumbuhkan Pelaku Utama Antikorupsi & Melakukan analisis kasus tipikor \\
\hline 13 & Mengorganisasikan Kelompok Sasaran & $\begin{array}{l}\text { Menganalisa metodologi organisasi } \\
\text { sasaran }\end{array}$ \\
\hline 14 & Membangun Komunikasi Kelompok Sasaran Penyuluhan & Meningkatkan kinerja penyuluhan \\
\hline 15. & Menumbuhkan Jejaring Kerja Antara Kelompok Sasaran & Menganalisa kinerja antar kelompok \\
\hline 16 & Melakukan Kolaborasi & $\begin{array}{l}\text { Membangun teamwork kelompok } \\
\text { sasaran }\end{array}$ \\
\hline 17 & Memobillsasi Gerakan Antikorupsi & $\begin{array}{l}\text { Meningkatkan renstra kelompok } \\
\text { sasaran }\end{array}$ \\
\hline 18 & Pelaksanaan Penyuluhan Antikorupsi & Menganalisa proses penyuluhan \\
\hline 19 & Memantau Pelaksanaan Penyuluhan Antikorupsi & Menganalisa praktek penyuluhan \\
\hline 20 & Memfasilitasi Penguatan Kapasitas Kelembagaan dan Kelompok & $\begin{array}{l}\text { Membangun komunikasi antar } \\
\text { lembaga }\end{array}$ \\
\hline
\end{tabular}

Sumber: Data Primer LSP P3 PIB, 2021

\section{Hasil dan Pembahasan}

Kegiatan PKM ini terselenggara didanai program Hibah PSKK yang dilaksanakan pada bulan Januari hingga Mei 2021. Kegiatan PKM melibatkan 47 orang Asesor dari LSP P3 PIB. Diawali dengan sosialisasi program dalam Orientasi Umum atau sejenis kuliah umum dan diskusi ilmiah terkait gambaran mengenai kesenjangan persepsi dari para Asesi sebagai mitra PKM, terutama mengenai sepuluh masalah di atas. 


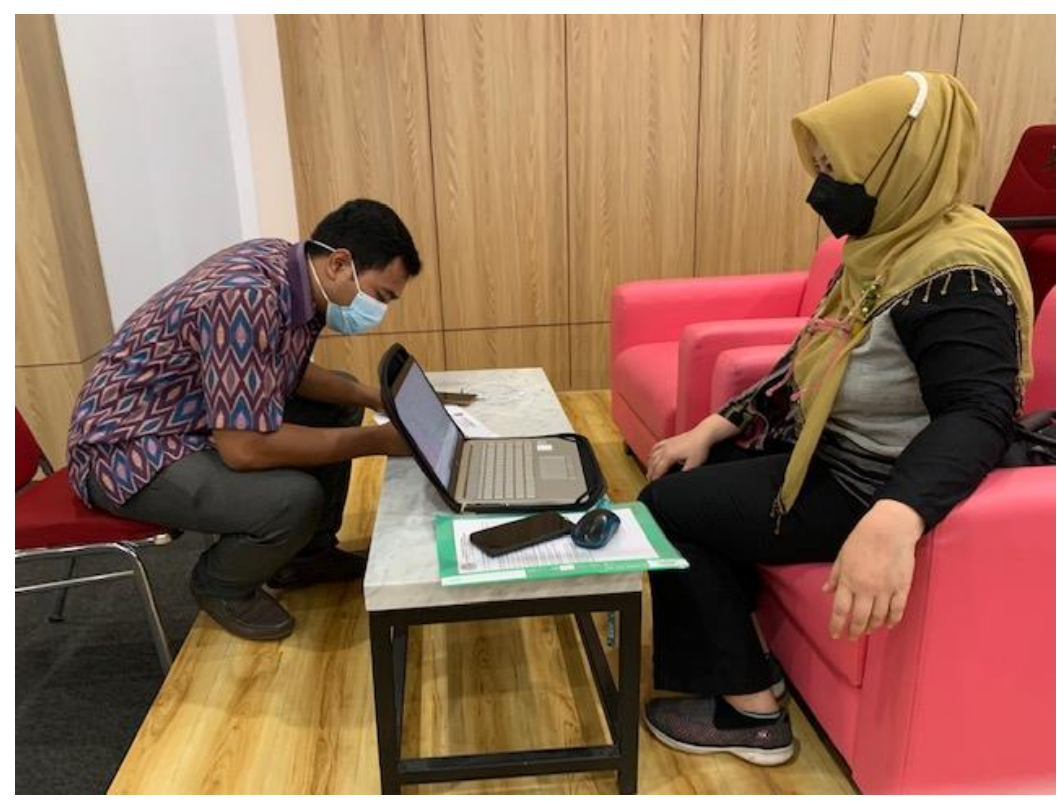

Gambar 1. Proses Pengisian APL-01 PKM sertifikasi BNSP Penyuluh Antikorupsi

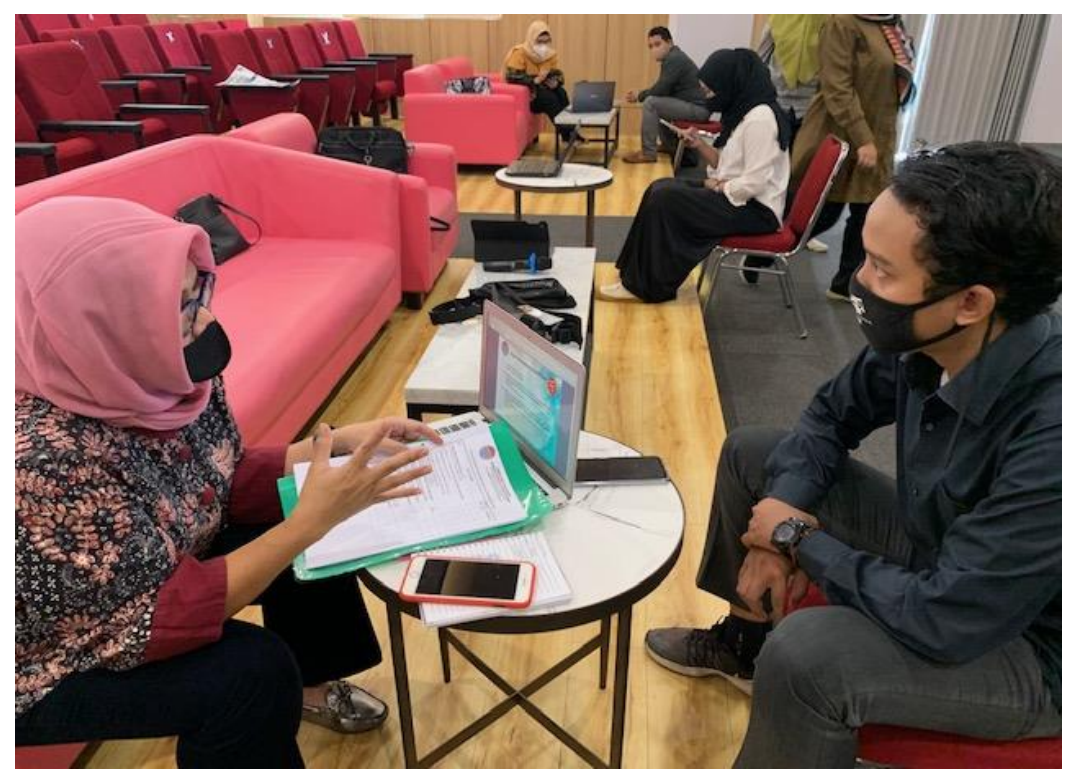

Gambar 2. Proses Pra Asesmen PKM sertifikasi BNSP Penyuluh Antikorupsi 


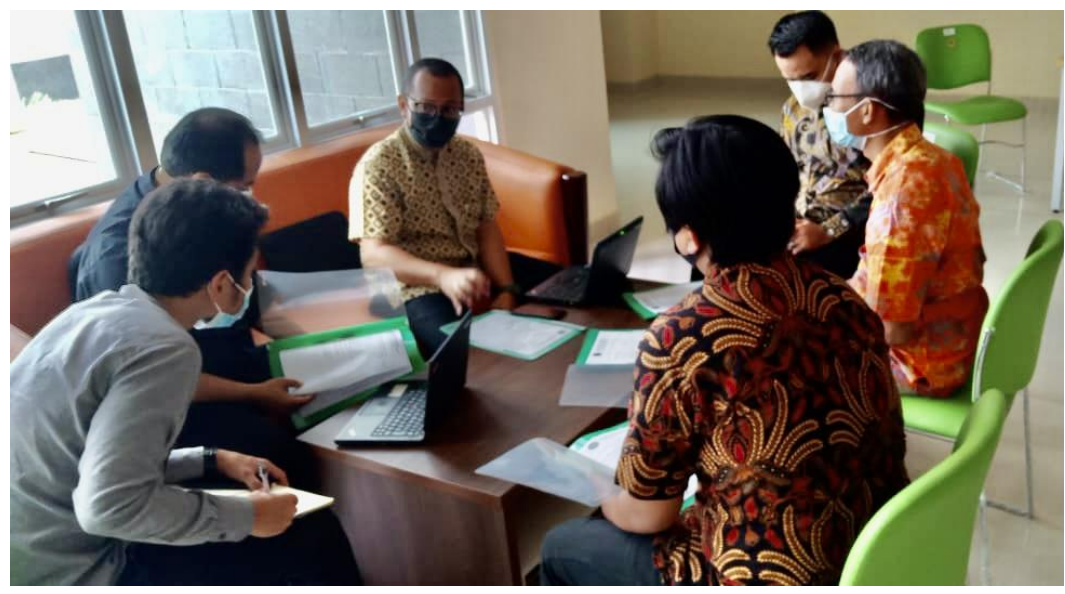

Gambar 3. Proses Validasi dan Verifikasi PKM Sertifikasi BNSP Penyuluh Antikorupsi

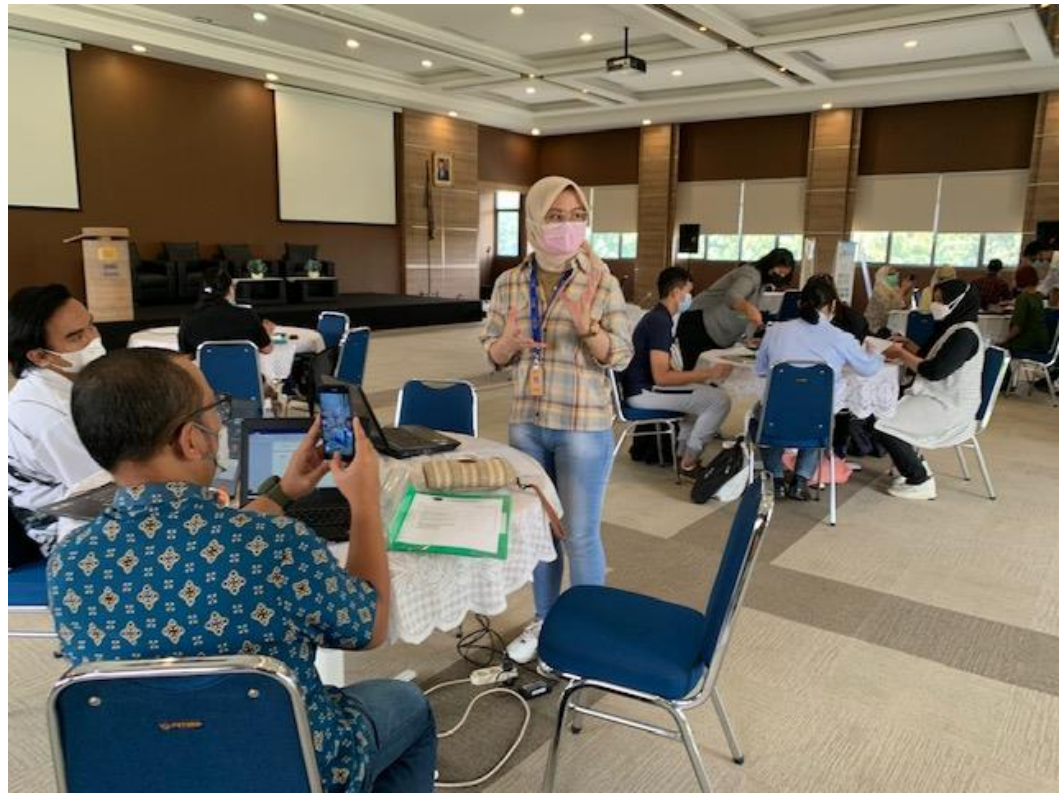

Gambar 4. Proses Pra Uji Kompetensi PKM sertifikasi BNSP Penyuluh Antikorupsi 


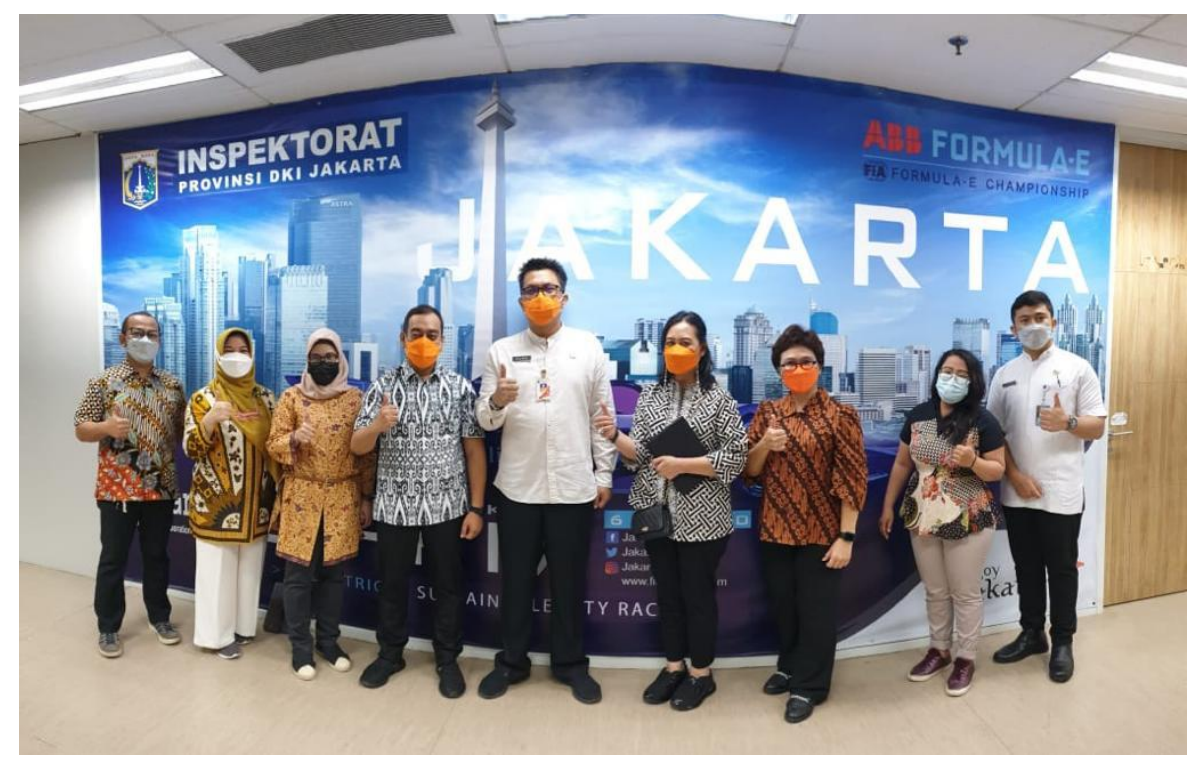

Gambar 5. Prosesi Penutupan Sertifikasi

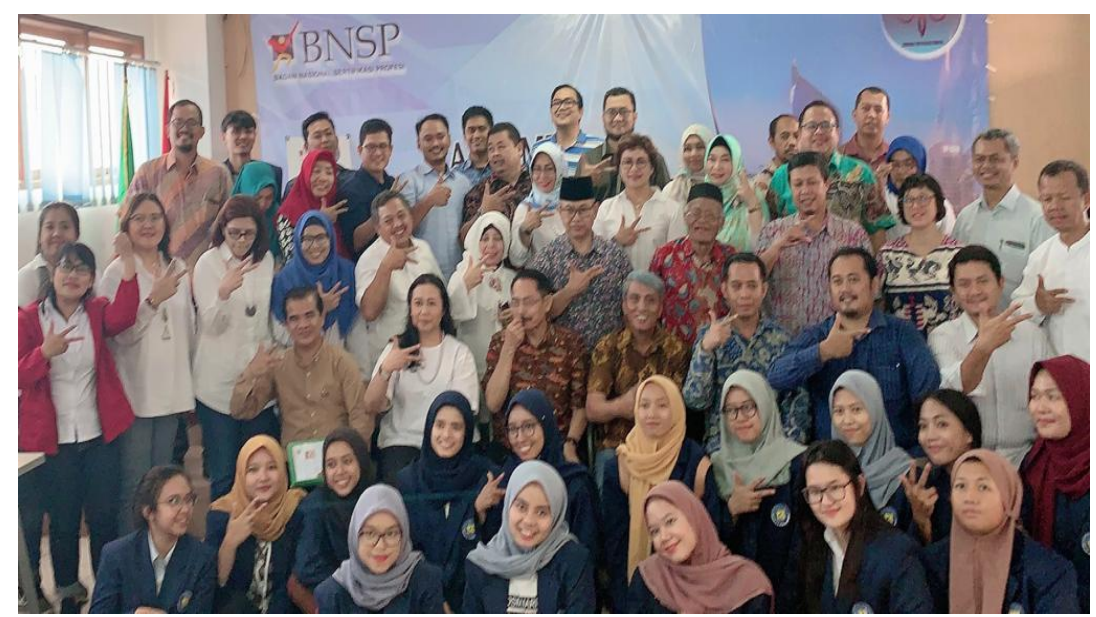

Gambar 6. Pembacaan Pakta Integritas

Kegiatan PKM ini dilaksanakan secara bertahap, yaitu setiap hari melibatkan sekitar kurang lebih empat puluh Asesi dan berlangsung hingga bulan Mei 2021. Tahap pertama seperti pada Bagan Gambar 1. yaitu pengisian APL-01, verifikasi kelengkapan dokumen persyaratan, lalu memasuki tahapan penandatanganan AFR 01 yaitu kesediaan Asesi untuk mengikuti proses Sertifikasi BNSP serta, dulanjutkan dengan Uji Kompetensi yang tertuang pada MAPA-1 berdasarkan MUK (Materi Uji Komoetensi) pada proses sertifikasi. Setelah dinyatakan lolos pra asesmen, maka para Asesi diminta untuk mengikuti Uji Kompetensi yang terdiri dari dua bagian; 1) Uji Komepetensi Presentasi Aspek K3 dan Presentasi Materi Penyuluh, 2) Uji Kompetensi Komprehensif. Para Asesor akan meyediakan pertanyaan dan melakukan observasi yang dinilai oleh para Asesor lain, lalu dirapatkan pada rapat sidang pleno, diikuti dengan pengumuman kompetensi dan terakhir adalah proses distribusi atau pembagian sertifikat. Semua prosesi sertifikat BNSP diakhiri dengan penyusunan laporan guna pengusulan Asesi yang Kompeten untuk diusulkan blanko Sertifikat atas nama Asesi yang dianggap Kompeten.

PKM ini dilakukan untuk memenuhi unsur edukasi dan prevensi masyarakat terhadap bahaya korupsi yang marak terjadi di Republik Indonesia tercinta, diseminasi atau sosialisasi pengetahuan akan kesadaran pencegahan tindak pidana korupsi bagi para Asesi bertujuan untuk membekali Asesi dalam 
melakukan syiar terhadap betapa buruknya dampak korupsi. Untuk membangkitkan semangat perlawanan masyarakat terhadap tindak pidana korupsi perbuatan busuk yang kategorikan sebagai tindak kejahatan luar biasa atau eraordinary crime (Klitgaaard, 2019).

Ada 7 (tujuh) pengelompokan delik yang tertuang pada UU 20/2001 antara lain; terjadinya kerugian keuangan negara, suap menyuap, penggelapan dalam jabatan, pengadaan barang dan jasa yang curang, pemerasan dan gratifikasi. Untuk itu peningkatan kompetensi Penyuluh Antikorupsi, agar masyarakat berperan aktif dalam menegeakkan hukum serta membentuk negara yang berdaulat, berdemokrasi dan meningkatkankesejahteraan masyarakat Indonesia pada umumnya. Terutama dalam meningkatkan rasa kebangsaan dan patriotisme diri demi meningkatnya kemaslahatan kesejahteraan bangsa.

Upaya pemberdayaan melalui wujud nyata PKM, membantu Akademisi untuk berpikir kritis, membuka wawasan kebangsaan, disamping itu PKM Sertifikasi BNSP ini merupakan bekal bagi bagi penyuluh antikorupsi. PKM ini memiliki nilai tambah ekonomis dan Sertifikasi BNSP yang prestisius.

Tabel 5. Target Luaran PKM Sertifikasi BNSP Penyuluh Antikorupsi

\begin{tabular}{|l|l|l|}
\hline No. & Target Jenis Luaran & Publikasi pada Jurnal Nasional Terakreditasi \\
\hline 1. & Publikasi Ilmiah Nasional & IJFAM Scopus Q2 2656-3355 \\
\hline 2. & $\begin{array}{l}\text { Prosiding, Internasional } \\
\text { Conference }\end{array}$ & $\begin{array}{l}\text { Sosialisasi Penyuluh Integritas Sertifikasi } \\
\text { Penyuluh LSP P3 PIB secara Nasional }\end{array}$ \\
\hline 3. & Desiminasi Program Sertifikasi & \\
\hline
\end{tabular}

Sumber: Data diolah sendiri, 2021

\section{Kesimpulan}

1. Aktifitas Pengabdian Kepada Masyarakat yang berjalan sesuai rencana, total Asesi adalah 800 orang dari kalangan Akademisi

2. Penyelenggaraan dilakukan secara profesional

3. Asesi dan Asesor tidak saling mengenal

4. Tanggapan para Asesi terhadap penyelenggaraan program Sertifikasi ini sangat positif

5. Kegiatan Program Sertifikasi ini diyakini sangat efektif dalam membangun lingkungan yang madani

\section{Saran}

Berdasarkan evaluasi yang telah dilakukan dapat diajukan beberapa saran sebagai berikut:

1. Pelaksanaan aktivitas PKM yang bertujuan mengedukasi masyarakat, wajib dilakukan secara masif dan terstruktur

2. Pelaksanaan lanjutan PKM berupa program sertifikasi harus digalakkan, mengingat masyarakat yang masih awam sama sekali tidak memiliki pengetahuan perihal semua yang terkait tindak pidana korupsi terutama perbedaan suap menyuap, pemerasan dan gratifikasi

3. Program Sertifikasi BNSP Penyuluh Antikorupsi ini bermanfaat sebagai upaya preventif dan edukasi terhadap lingungan dimanapun Asesi berada, sehingga wajib diadakan secara berkala

4. Wajib dicetak Penyuluh Antikorupsi sebagai profesi mensosialisasikan bahaya, upaya pencegahan dan pemberantasan korupsi di semua lapisan masyarakat

5. Informasi pendidikan Antikorupsi dengan menerapkan tata nilai yang luhur, wajib diawali sejak usia dini 
6. Penerapan tata nilai wajib dimulai dari pendidikan Dasar hingga pendidikan tertinggi masyarakat, dengan menjalankan kejujuran, kedisiplinan, sifat saling membantu, bertanggung jawab, memiliki kepedulian dan kemandirian di dalam diri masing-masing individu

7. Sertifikat BNSP Penyuluh Antikorupsi bagi lulusan Perguruan Tinggi mempermudah mencari pekerjaan, karena merupakan wujug Surat Keterangan Pendamping Ijazah (SKPI) dalam bentuk nyata (Permendikti No. 44, 2012)

\section{Referensi}

Bologne, J. (2018). Handbook on Corporate Fraud: Prevention, detection, and investigation: Butterworth-Heinemann. 10th Edition.

Cressey, D. (2018). Other People's Money; A Study In The Social Psychology Of Embezzlement. Glencoe, IL: Free Press. 15th Edition.

Indonesia, P. R. (2001). Undang-Undang Republik Indonesia Nomor 20 Tahun 2001 Tentang Perubahan Atas Undang-Undang Nomor 31 Tahun 1999 Tentang Pemberantasan Tindak Pidana Korupsi.

Indonesia, R. (2017). Peraturan Presiden Republik Indonesia nomor 87 tahun 2017 tentang penguatan pendidikan karakter. Jakarta: Kementerian Sekretariat Negara Republik Indonesia.

Klitgaard, Robert. (2019). Controlling Corruption. University of California Press. 12th Edition.

Klitgaard, Robert. (2000). Ronald Maclean-Abaroa, H. Lindsey Parris, Corrupt Cities, A Practical Guide to Cure and Prevention, Institute Contemporary Studies Oakland, California, World Bank Institute

Peraturan Badan Nasional Sertifikasi Profesi Nomor 2/BNSP/III/2014 tentang LSP (Lembaga Sertifikasi Profesi)

Standar Kompetensi Kerja Nasional Indonesia, 2016. No. 303 Penyuluh Antikorupsi - Keputusan Menteri Ketenagakerjaan Republik Indonesia Nomor 303 Tahun 2016 Tentang Penetapan Standar Kompetensi Kerja Nasional Indonesia Kategori Aktivitas Profesional, Ilmiah, Dan Teknis Golongan Pokok Aktivitas Profesional, Ilmiah, Dan Teknis Bidang Penyuluhan Pada Jabatan Kerja Penyuluh Antikorupsi

The Strategic Meeting of The Ad-Hoc Task Force. Majalah Sertifikasi Edisi Kedua. Jakarta: BNSP.

Transparancy International, 2021. Research Annual Report of 2021.

Wolfe, David T. Dana R. Hermanson. 2004. The Fraud Diamond: Considering The Four Element of Fraud. CPA 